\title{
Memória e identidade: o processo de sucessão e herança no Mercado Municipal de Montes Claros - MG, Brasil
}

\author{
Thaynara Thaissa Dias Guimarães \\ Universidade Federal de Santa Maria, Brasil \\ thaynara.dias@hotmail.com

\section{Sheila Maria Doula} \\ Universidade Federal de Viçosa, Brasil \\ sheila@ufv.br
}

Cita sugerida: Guimarães, T. T. D. y Doula, S. M. (2018). Memória e identidade: o processo de sucessão e herança no Mercado Municipal de Montes Claros - MG, Brasil. Mundo Agrario, 19(40), e078. https://doi.org/10.24215/15155994e078

Recibido: 30 de junio de 2016 - Aceptado: 23 de agosto de 2017 - Publicado: 26 de marzo de 2018 


\section{Memória e identidade: o processo de sucessão e herança no Mercado Municipal de Montes Claros - MG, Brasil}

Memory and Identity: the process of succession and inheritance in the Municipal Market of Montes Claros - MG, Brazil

Thaynara Thaissa Dias Guimarães

Universidade Federal de Santa Maria, Brasil

thaynara.dias@hotmail.com

Sheila Maria Doula

Universidade Federal de Viçosa, Brasil

sheila@ufv.br

\section{ReSUMO:}

Esta pesquisa visa compreender as representações sociais sobre o processo de sucessão e herança das barracas e da profissão de feirante no Mercado Municipal de Montes Claros - MG, Brasil. Utiliza-se a metodologia qualitativa com pesquisa bibliográfica, pesquisa documental e entrevistas semi-estruturadas com um total de 8 feirantes. Através dos resultados conclui-se que a transmissão da profissão de feirante é um processo que se desenvolve no cotidiano, através da evocação da memória e de práticas que perpassam gerações. Por sua vez, a transmissão do patrimônio material está vinculada à gestão econômica e à história das famílias. PalaVras-ChaVe: Brasil, Representações sociais, Patrimônio, Mercado municipal, Brasil.

\section{Abstract:}

This research aimed to understand the social representations about the process of succession and inheritance of tents and marketer profession in the Municipal Market of Montes Claros - MG, Brazil. It is used the qualitative methodology with literature review and documentary research. Also were used for data collection semi-structured interviews conducted in depth with a total of 8 marketers. Through the results it was observed that the transmission of the marketer profession is a process that happens in everyday life, through the memory evocation design and practices that run through generations. On the other hand, the transmission of the material heritage is bonded to economic management and the history of families.

KEYWORDs: Brazil, Social representations, Patrimony, Municipal market.

\section{INTRODUÇÃo}

A história dos mercados está vinculada à Grécia Antiga com a formação da Ágora, com os fóruns romanos e, posteriormente, com os mercados medievais. Tais lugares são emblemáticos não apenas pela relação que se estabelece entre cidade e comércio, mas, sobretudo por representarem ambientes de intensa sociabilidade, cujas características mais definidas são a diversidade e a concentração de atividades, que são marcadas pela "convergência de práticas sociais, (...) no ponto de encontro de fluxos de pessoas e de seus excedentes de produção" (Filgueiras, 2006, p. 25).

$\mathrm{Na}$ Idade Média a praça do mercado tornou-se arquitetonicamente uma conjunção urbana e rural, agregando mercadores e mercadorias, sendo fundamental para o desenvolvimento das cidades. O processo de troca ganhou ainda mais força quando os alimentos excedentes originados da melhoria da produção agrícola feudal passaram a ser comercializados nas cidades durante as feiras. O surgimento e a evolução das relações de mercado atribuíram uma nova definição social à atividade comercial, passando a feira a ser essencial para a disposição espacial da sociedade, uma vez que se instituiu o elo entre produção e consumo (Nagel, Gonçalves, Ranger, e Peçanha, 2007; Filgueiras, 2006).

No Brasil, as feiras livres consistem em um tipo de mercado varejista ao ar livre que ocorre semanalmente, em espaços abertos das ruas, em cada dia em um lugar diferente, destinada a distribuição local de alimentos 
e produtos básicos. Segundo Mascarenhas (2008), a feira livre brasileira tem sua herança na tradição ibérica e também nas práticas africanas populares chamadas de quitandas, do quimbundo kitanda, que significa mercado; regularmente presentes nas cidades brasileiras desde o início do período colonial, constituíam agrupamentos de negras ao ar livre, acocoradas ou dispondo de tabuleiros, que comercializam produtos de pequenas lavouras e pescas.

A partir da década de 1860, no entanto, o Brasil começa um processo de institucionalização das trocas comerciais em feiras livres, dando origem aos espaços denominados de mercados municipais ou mercados centrais. Popularmente chamado apenas de mercado, este é um espaço fixo, coberto, com horário de funcionamento predefinido, onde as barracas e os feirantes permanecem todos os dias. O mercado passa a existir no Brasil quando o Distrito Federal decidiu pela multiplicação dos mercados cobertos e, em meados de 1870, essa conformação ganhou real incentivo com as doações de terrenos públicos para sua construção. O objetivo de tal ação era possibilitar maior fiscalização pública e controle das atividades varejistas (Mascarenhas, 2008).

Apesar de a feira livre e o mercado apresentarem distinções na conformação do espaço físico, os trabalhadores de mercados municipais e feiras livres se autodenominam feirantes, pois têm como denominadores comuns o trabalho familiar, as barracas e o contato face a face com o consumidor. Logo, o mercado, como espaço público, cumpre simultaneamente duas funções, como aponta Hansen (2002), "a troca de bens e a troca de ideias e experiências sociais" (p. 2).

Os mercados são, portanto, considerados a forma mais antiga de comercialização, de encontro de pessoas, de saberes e práticas que persistem até os dias atuais; no entanto, este tipo de comércio foi perdendo espaço à medida que as sociedades foram modificando as formas de comercialização, consumo e produção de alimentos e criando outros formatos de varejo de alimentos, como as redes de supermercados, os varejóes e os sacolões ${ }^{1}$, que ganharam mais espaço diante das alterações de hábitos e comportamento das sociedades contemporâneas (Cazane, Machado e Sampaio, 2014).

Desse modo, a existência e persistência dos mercados nos dias atuais está vinculada à ideia de que este é um espaço não só de comercialização, mas também de socialização, de cores, cheiros e sons que fazem parte da história das pessoas e das cidades nas quais estão inseridos. O mercado surge da necessidade da troca e do intercâmbio de saberes e práticas (Servilha, 2008) que são construídos através do cotidiano e formam o patrimônio cultural e imaterial das cidades.

Este artigo parte do pressuposto que o mercado, como todas as instituições sociais, é perpassado pela constante passagem das gerações, o que implica em problematizar as condições de sua reprodução social, posto que as novas gerações atribuem diferentes significados aos patrimônios já construídos. Como aponta Karl Mannheim (1982), a cultura é desenvolvida por indivíduos que entram em contato de diferentes maneiras com o patrimônio cultural herdado. O processo de se transferir de geração a geração os patrimônios materiais e imateriais, as heranças e acúmulos culturais de um grupo como os feirantes, por exemplo, irá refletir na continuidade do próprio mercado.

Um lugar tão dinâmico, que incorpora diferentes configurações de grupos e significados, pode ser compreendido através de diversas representações sociais. Segundo Denise Jodelet (2001), as representações sociais devem ser compreendidas através da ótica de vários elementos, como a afetividade mental e social, levando-se em consideração a realidade material, social e ideativa sobre a qual a representação intervém. As representações sociais guiam a maneira de se nomear, definir e interpretar os diferentes aspectos da realidade, como por exemplo, a escolha entre herdar o patrimônio material e imaterial do mercado e orientar um projeto de vida profissional tornando-se um feirante ou não.

O presente artigo analisa as representações dos feirantes do Mercado Municipal de Montes Claros - MG sobre o processo de sucessão e herança das barracas e da profissão de feirante, considerando a memória e as relações intergeracionais em um espaço que, como afirmou Beatriz Filgueiras (2006), é repleto de trocas simbólicas, práticas sociais, encontros e diversidade social, mas que está inserido em um tempo que possui 
novas concepções sobre as condições de vida e o trabalho, as quais causam modificações no imaginário e no comportamento de indivíduos (Garcia, 2003).

As discussões deste artigo são pautadas na teoria das representações sociais (Jodelet, 2001; Froehlich, 2002; Candau, 2005) e teve como metodologia a pesquisa bibliográfica, a pesquisa qualitativa composta pela pesquisa documental e entrevistas semiestruturadas, guiadas pela bibliografia de referência, realizadas com os feirantes do Mercado Municipal de Montes Claros - MG, Brasil, ao longo de julho de 2015

\section{A MEMÓRIA E AS TEORIAS DAS REPRESENTAÇÕES SOCIAIS}

Através das representações sociais, segundo Jodelet (2001), é possível compreender as formas de comportamento, bem como as orientações de ordem cultural (religiosa, econômica, moral, estética, etc.) que regem as ações individuais, coletivas e as interações da vida social. O ser humano vive em um mundo composto de objetos, pessoas, acontecimentos, ideias; divide as suas visões do mundo com outras pessoas que se ajudam mutuamente para entender, gerir ou confrontar esse mundo, seja através do conflito ou através de uma visão em comum, pois, como aponta Maurice Halbwachs (1990), “na realidade, nunca estamos sós” (p. 26). Para Evandro Araújo e Elisa Ichikawa (2011), as representações sociais se desenvolvem através das interações e comunicações humanas e também pelas implicações afetivas, interiorizadas através das experiências, práticas e normas que, por sua vez, acabam por formar ou reforçar representações já existentes.

Neste sentido, a memória é uma representação social do passado. Joel Candau (2005) aponta a memória como uma reorganização contínua e atualizada do passado, que armazena uma série de eventos vivenciados pelos indivíduos e grupos, e que se converte em referência para a construção das identidades. Para o autor, memória e identidade são indissociáveis, visto que a identidade se manifesta pelo discurso que é respaldado pelos acervos acumulados. A memória pode ser dividida em protomemória e metamemória; a primeira se refere ao que o autor denomina de memória de baixo nível, processual, ligada ao hábito, enquanto a segunda representa o que cada indivíduo faz de sua própria memória e o que fala sobre ela, em uma ação de ligação entre o ser e seu passado.

Podemos afirmar então que as pessoas são formadas pela sua história, a história é formada pelas lembranças, as lembranças são formadas pela memória. Em função de tal movimento, Halbwachs (1990) afirma que a memória é coletiva. As lembranças não são rememoradas apenas por nós mesmos, mas também pelos outros, ainda que esta recordação esteja relacionada com algo que apenas nós vivemos ou com algo que apenas nós vemos. Para o autor, "não é necessário que outros homens estejam lá, que se distingam materialmente de nós: porque temos sempre conosco e em nós uma quantidade de pessoas que não se confundem” (Halbwachs, 1990, p. 26).

Os elementos constituintes da memória - seja individual ou coletiva -, segundo Michael Pollak (1992), são primeiramente os acontecimentos vividos pessoalmente, em seguida, os acontecimentos denominados pelo autor como vividos por tabela, ou seja, são "acontecimentos dos quais a pessoa nem sempre participou, mas que, no imaginário, tomaram tamanho relevo que, no fim das contas, é quase impossível que ela consiga saber se participou ou não" (p. 201). Para Candau (2005), as memórias podem ser partilhadas e herdadas. $\mathrm{O}$ autor afirma que as lembranças individuais estão intimamente relacionadas com as lembranças de outras pessoas dentro de um mesmo grupo; assim, um conjunto de recordações partilhadas são interpretadas e evocadas individualmente de diferentes formas, tendo em conta as escolhas de cada um, dentro de uma grande quantidade de convenções que permitem a evocação de uma lembrança.

Emília Godoi (1999) concorda com Candau e ambos afirmam que a memória é identidade e é portadora do imaginário. A memória é formulada através do cotidiano e das pessoas que participam dele, dando origem a uma história criada através do universo simbólico dos sujeitos e das condições sociais nas quais estão inseridos. Godoi (1999) afirma que a memória coletiva se distingue da memória individual por ser a organização ativa das experiências vividas, e justamente por isso se inscreve no tempo e no espaço. O espaço 
serve como um norteador do tempo, pois não é apenas um local das coisas, mas constrói um sistema coeso de imagens coletivas. Por sua vez, Pierre Nora (1993) aponta que toda memória edificada por um grupo pode ser traduzida através do lugar, pois cada lugar possui um sentido compreensível somente para os membros do grupo. Cada parte desse espaço foi ocupada pelo grupo e marcada como um tempo por eles vivido.

Além da importância dos lugares para a formação da memória, Godoi (1999) afirma existir outro nível a ser levado em consideração: os laços familiares. Para ela, estes laços permitem que determinado grupo, dono de uma memória coletiva, que utiliza de lugares de memória, possa ter continuidade. Nesse caso, fazer parte da família não significa apenas ter laços de consanguinidade, mas também, como aponta Guillermina Ferraris (2011), partilhar de normas de comportamentos e ações que estão ligadas diretamente à construção de identidade do grupo, logo, estão ligadas à construção da memória coletiva.

A memória pode transitar entre diferentes espaços, tempos e universos culturais. Segundo Froehlich (2002), esse transitar permite a construção e redefinição de identidades sociais, pois as pessoas deixam de pertencer a um só grupo ou localidade; esse processo de trocas culturais admite rejeições, reinterpretações e novas acomodações simbólicas que reforçam o caráter dinâmico do campo das representações.É pautado por essa concepção de universo simbólico e ações guiadas por significados que este artigo analisa o processo de sucessão e herança familiar dos feirantes do Mercado Municipal de Montes Claros, utilizando as representações sociais para organizar os comportamentos e diálogos sociais.

\section{O MERCADO MUNICIPAL E O FEIRANTE}

Espaços como mercados municipais e feiras livres, segundo José Angulo (2003), são locais de representações e de socialização carregados de histórias e de símbolos. Nestes locais, conforme os apontamentos de Angulo, encontramos características vinculadas às condições de trabalho, organização e consumo, origem e destino dos produtos passíveis de comercialização. São pontos de conexão entre a cidade e o campo, que sustentam uma relação ativa entre diferentes setores. Como resultado, os mercados municipais se mostram como um local de encontro entre pessoas e destas com os produtos regionais (Silvestre, Ribeiro e Freitas, 2011). Há nesse caso uma diferenciação dos produtos comercializados, e essa distinção está ligada à origem desse produto, pois o valor do local frente ao global, do rural frente ao urbano, do endógeno diante do exógeno, do pessoal frente ao anônimo, do artesanal frente ao industrial ganha destaque e é resultado de uma interação entre o espaço e a cultura do grupo de referência no qual se comercializavam os produtos (Cordisco, 2013). Sendo assim, mercados municipais e feiras livres, segundo Fávio Sacco dos Anjos (2005), representam uma das características mais marcantes na edificação cultural das sociedades que dela compartilham. Diante de um tempo marcado por transformações sociais, culturais e econômicas, estes espaços lidam com inúmeras provocações a sua competente constância, trata-se de um lugar de transações econômicas e de sociabilidade entre produtores, feirantes e consumidores.

Pode-se afirmar que são inúmeras as relações de trocas existentes em um espaço como o mercado municipal. Servilha (2008) aponta que estas são materiais, simbólicas, econômicas e não econômicas, e podem ser compreendidas através da vida cotidiana do mercado e dos feirantes. Assim, o mercado municipal está inserido em uma economia de trocas simbólicas, pois, como aponta Pierre Bourdieu (2009), a produção de bens simbólicos está ligada à "diversidade dos públicos aos quais as diferentes categorias de produtores destinam seus produtos” (p. 102), logo, a circulação de bens simbólicos pode ser compreendida "como o sistema de relações objetivas entre diferentes instâncias definidas pela função que cumprem na divisão do trabalho de produção, reprodução e de difusão de bens simbólicos" (Bourdieu, 2009, p. 102). Ou seja, as trocas que ocorrem no mercado estão vinculadas à construção social dos sujeitos que trabalham e frequentam esse espaço. Logo, são distintas as trocas e também as identidades que constituem esse lugar e, portanto, o mercado não pode ser analisado exclusivamente através das relações econômicas, visto que os capitais simbólico e econômico se encontram mesclados. 
Os feirantes de mercados municipais, segundo Vedana (2013), podem ser identificados em várias categorias que a prática desse trabalho permite. $\mathrm{O}$ feirante é dono do próprio negócio, que se converte no negócio da família, lida com uma série de conhecimentos "sobre economia, agricultura, alimentos, importações, etc., vai além dos limites do mercado, colocando esse trabalhador em sintonia com os processos de globalização e transformações sociais, econômicas e urbanas" (Vedana, 2013, p. 5). Ser feirante é mais do que uma ocupação momentânea, é uma profissão escolhida, construída através de trajetórias, relações de trabalho, partilha de redes e conhecimento. A autora considera que o "fazer-se feirante" é parte de um projeto conjunto entre individual e coletivo, que se forma através das experiências vividas, da herança das aprendizagens e das idas e vindas em outros empregos.

As relações diárias dos feirantes, segundo Samuel Melo (2013), transcorrem gerações. Por isso, ao realizar uma discussão geral acerca dos jovens feirantes e das suas representações sobre o próprio espaço social, o sociólogo percebeu que sonhos e desejos projetados e internalizados vivem em diálogo com os valores da tradição construídos no interior da família e os valores da modernidade. Segundo o autor, jovens inseridos nesse espaço reinventam e reinterpretam as tradições, produzem e reproduzem significados sobre a continuidade e as modificações das relações sociais.

Seguramente, os mercados municipais, que outrora representavam o centro econômico e estimulavam as cidades em crescimento, não possuem mais este significado e importância econômica. Se ainda persistem, é porque se tornaram parte da história local e assim resistiram às imposições da modernização; são tomados como patrimônio e considerados símbolos da história econômica e cultural das cidades e de sua região de influência, compostos por memórias, histórias e diversas representações sociais.

\section{HERANÇA E SUCESSÃo FAMILIAR}

O processo sucessório possui diferentes características e consiste na transferência de poder e de patrimônio entre gerações (Chemin e Ahlert, 2010). Não apenas bens materiais são transmitidos, como afirma Carneiro (2001), mas, também bens simbólicos são passados de uma geração a outra. O processo de herdar e suceder pode ocorrer conjuntamente e estar centrado em uma única pessoa, como também pode acontecer separadamente, em diferentes momentos e com pessoas distintas (Chemin e Ahlert, 2010).

Suceder e herdar são ações geridas por normas, mas é preciso compreender que diferentes práticas sustentam a lógica de transmissão de patrimônio, e, portanto, não devem ser compreendidas apenas dentro da formalidade. Esses processos se modificam de acordo com a realidade de cada família, que cria inúmeras possibilidades de soluções “fruto não apenas de diferentes tradições, mas, sobretudo, de diferentes sistemas de reprodução cultural, social e econômica. Nestes termos, não existe uma rigidez de regras nem uma diversidade descontextualizada" (Carneiro, 2001, p. 23).

Diante da diversidade de soluções, não é sem contradições e tensões que ocorre a transmissão da herança e sucessão. Até o final dos anos de 1960, Milton Silvestro et al. (2001) afirmam que as famílias tinham grande influência moral sobre a escolha dos filhos. Atualmente, as decisões dos jovens rurais estão vinculadas a uma série de fatores, como por exemplo, a perspectiva de geração de renda através do patrimônio da família comparada com o que acreditam que poderiam obter inserindo-se em mercados de trabalho assalariado.

Assim, ao longo do tempo, a hierarquia da organização familiar tradicional cria novas conformações, com a dissolução do poder absoluto do pai e dando espaço à maior participação de todos os membros da família, permitindo discussões sobre a gestão de patrimônios e de processos sucessórios (Silvestro et al., 2001). Para entender as diferentes lógicas que perpassam os processos sucessórios é necessário buscar os diferentes significados que o próprio patrimônio possui (Carneiro, 2001).

O patrimônio imaterial, o conhecimento e o saber-fazer também compõem a herança e transmissão de uma geração para outra. Karl Mannheim (1982) afirma que é preciso repassar para as novas gerações, sentimentos, atitudes, e esse processo deve ocorrer através do ensino consciente e inconsciente, transmitidos de forma 
involuntária. É essa transmissão involuntária que irá permitir que as sociedades continuem se reproduzindo. Uma sociedade precisa lidar com a morte constante dos antigos que conhecem a tradição, e com a dificuldade de possuir diferentes gerações no processo de formação histórica, que podem aceitar, modificar ou rejeitar os patrimônios construídos pelas gerações antecessoras. Contudo, é inegável que este movimento é delicado e pode ser doloroso.

As diferentes configurações do processo sucessório tornam essa fase de passagem patrimonial conflituosa, o que reflete diretamente na trajetória social dos indivíduos e de seu grupo doméstico. É preciso levar em conta todos os fatores sociais que cercam essa discussão: de um lado, a "dimensão macroestrutural (com componentes sociais, econômicos, políticos e institucionais) e, por outro, um sistema cultural com raízes históricas que é continuamente reproduzido e/ou redefinido pelos diversos segmentos" (Stropasolas, 2013, p. 8).

\section{Metodologia}

Este artigo teve como ponto de partida a pesquisa qualitativa, por considerá-la capaz de compreender o "universo dos significados, dos motivos, das aspiraçóes, das crenças, dos valores e atitudes (...) dentro e a partir da realidade vivida e partilhada" (Minayo, 2010, p. 21). Assim, utilizou-se da bibliografia de referência para compreender a teoria acerca de representações sociais, sucessão familiar e mercados municipais. O objeto empírico dessa pesquisa é o Mercado Municipal da cidade de Montes Claros localizada no estado de Minas Gerais, região sudeste do Brasil.

A cidade de Montes Claros atualmente é considerada um polo regional que agrega mais de 2 milhões de habitantes das cidades circunvizinhas. De acordo com dados do ano de 2010 do Instituto Brasileiro de Geografia e Estatística, a população da cidade era de 361.915 pessoas. A população rural representava 6 $\%$ do total, o que equivalia a 17,8 mil pessoas. A economia local é sustentada pelo comércio, responsável por abastecer 150 cidades que fazem parte de seu entorno, pelas atividades industriais, e pelas atividades de prestação de serviços, que agrupam empresas de pequeno, médio e de grande porte. Há ainda a agricultura, que se destaca pela pecuária de corte e leite, e pelos cultivos de feijão, milho, mandioca e algodão.

A cidade de Montes Claros tem em sua história dois mercados municipais - o Mercado Velho, inaugurado em 1889, e o Mercado Novo, inaugurado em 1992. Segundo a Secretária de Desenvolvimento Econômico, Turismo, Ciência e Tecnologia (2010), o Mercado Novo possui uma área total de $21.450 \mathrm{~m}^{2}$ e há nele 135 boxes, além de 200 bancas livres no salão e parte externa do mercado, que comercializam desde hortifrutigranjeiros a conservas, especiarias e artesanatos. Entre segunda e quinta-feira, cerca de 5 mil pessoas circulam pelo local e aos finais de semana este número tende a duplicar.

Para melhor compreensão do objeto de pesquisa foi realizado um levantamento histórico, com consultas a arquivos públicos, acervos documentais e iconográficos. A pesquisa documental possibilitou compreender a inserção histórica do Mercado Municipal em Montes Claros, a sua consolidação como referência urbana, rural e regional, bem como as transformações estruturais e simbólicas pelas quais este espaço passou ao longo de sua existência.

Para a obtenção de dados em campo, utilizou-se a entrevista semiestruturada, realizada com 4 pais e 4 filhos, todos feirantes - que assim se auto denominaram nas entrevistas -, que são também agricultores e proprietários rurais, de ambos os sexos e diferentes graus de escolaridade, sendo estes 2 artesões, 2 comerciantes de hortifrutigranjeiros, 2 comerciantes de especiarias, 2 comerciantes de conservas. Estes feirantes têm filhos(as) que estão envolvidos no processo de comercialização das suas barracas ou que já haviam montado sua própria barraca no Mercado Municipal de Montes Claros.

O mercado funciona todos os dias da semana, tendo nos sábados maior movimento, com fregueses vindos também de outras cidades vizinhas. Os feirantes, donos de barracas fixas, foram abordados durante o funcionamento do mercado em dias de menor movimento e convidados a participarem do estudo. 
Foram esclarecidos acerca dos objetivos e métodos que seriam usados. Tão logo aceitaram o convite, foram entrevistados. Nas entrevistas procurou-se deixar os feirantes à vontade para tratar dos assuntos abordados (mercado, sucessão e memória). Para garantir a fidelidade dos dados, as entrevistas foram digitalmente gravadas e transcritas.

As entrevistas foram dividas em três eixos de perguntas. $\mathrm{O}$ primeiro caracterizou os entrevistados, o segundo eixo buscou compreender como os feirantes adquiriram as barracas, há quanto tempo e como se tornaram feirantes. O terceiro indagou sobre os processos de sucessão familiar e herança das barracas. Para os filhos dos feirantes seguiu-se a mesma metodologia, o primeiro eixo caracterizou os entrevistados, o segundo buscou compreender como estes aprenderam as atividades de produção e de comercialização. $\mathrm{O}$ terceiro relacionou a herança e sucessão das barracas com a escolha da profissão de feirante e o modo como interpretam a relação entre a continuação das barracas e a permanência da família no mercado. Os nomes dos feirantes entrevistados estão preservados, e quando citados são definidos por numeração.

As entrevistas foram transcritas na íntegra para delinear amplamente as experiências vividas e posteriormente foram analisadas através das lentes teóricas da representação social escolhidas para embasar este estudo.

\section{Resultados E Discuss Ão}

Os feirantes entrevistados pertencem a diferentes zonas rurais da cidade de Montes Claros; a mais distante delas se localiza a 38,9 km do mercado municipal. Dos 8 entrevistados, 3 são do sexo masculino e 5 do sexo feminino. Entre os homens há um entrevistado de 78 anos e dois entrevistados com 28 e 21 anos de idade. Entre as 5 mulheres entrevistadas três têm idade de 48, 55 e 60 anos, e duas com 23 e 29 anos de idade. O grau de escolaridade foi maior entre os mais jovens (de 21 a 29 anos de idade), que afirmaram possuir o ensino médio completo; já os mais velhos (de 48 a 78 anos de idade) têm o primário completo. Todos os entrevistados são casados e apenas um ainda não tem filhos.

Cada um dos feirantes entrevistados possui a sua própria barraca. Três delas foram obtidas diretamente na prefeitura e existem desde a formação do Mercado Velho; quando um novo local para o mercado municipal foi construído as barracas foram transferidas. As outras cinco barracas foram compradas diretamente de feirantes que decidiram se aposentar e/ou se mudar. Não foi possível saber quais as razões que levaram os comerciantes originais a vender as barracas.

Nesse caso, tanto a barraca quanto o espaço de comercialização são vendidos de forma ilegal entre os próprios feirantes, pois o direito de uso do espaço para comercialização no mercado só pode ser repassado entre membros de uma mesma família, em vida; caso contrário, a barraca é repassada à prefeitura que irá designar quem vai assumir o local. As barracas são reformadas e mobiliadas pelos feirantes quando as recebem, alguns colocam piso, pintam as paredes ou as hastes que a sustentam, além de montarem da forma que julgam ser mais atraente os artigos a serem comercializados, assim, quando vendem uma barraca, passam o ponto de comercialização, a estrutura já montada e que foi alterada e os artigos que ainda não foram comercializados.

Ao chegar ao mercado para conversar com os feirantes, sua primeira atitude foi apresentar o nome das suas barracas, que pode ser composto pelo nome do feirante ou pela mercadoria que comercializa, e/ou pelo nome da comunidade rural a qual pertence. Assim, quando uma barraca é passada de um feirante para outro, os nomes são modificados, porém, quando as barracas são herdadas pelos filhos, os nomes originais geralmente são mantidos. A relação que os feirantes estabelecem com os nomes que dão às barracas é sobretudo de pertencimento. Cria-se, como o nome, um vínculo direto com a origem do feirante, e principalmente com o reconhecimento de si e daquilo que ele oferta. Constata-se que o mercado é um "espaço físico e simbólico, onde os feirantes obtêm o reconhecimento individual e social, ou seja, como profissionais e também como pessoas" (Servilha, 2008, p. 140). 
Há uma valorização social das pessoas do mercado a partir de suas profissões. Essa valorização influencia diretamente na construção de suas identidades individuais, alicerçadas nos ofícios profissionais (Servilha, 2008), o que pode ser verificado na seguinte fala: "levei mais de ano para ter minha clientela, vai fazer 49 anos de barraca, e todo mundo sabe quem sou eu, de onde venho e o que vendo só de falar o nome da barraca e isso leva tempo" (Entrevistado 3,78 anos, Julho, 2015). Essa relação com o local de onde vieram, o produto que comercializam e o nome de suas barracas pode ser analisada pela teoria de Candau (2005) como uma memória reivindicada. Para o autor, as pessoas interagem com o mundo externo através da partilha de recordações e memórias. O nome das barracas significa a duração no tempo e é compartilhada de forma intersubjetiva, pois as relações, reações e interações sociais geram noções de pertencimento e reconhecimento que caracterizam a identidade de cada indivíduo.

Transmitir aos filhos a importância do elo entre o local de origem, o que comercializam e o reconhecimento que buscam de suas barracas faz parte da construção de uma memória incorporada que vem dos outros, dos pais, dos avós. Esta memória deve ficar na família e pode ser reconstruída, reinterpretada e ressignificada (Candau, 2005; Halbwachs, 1990). A memória herdada, segundo Pollak (1992), cria uma ligação entre o sentimento de identidade, tempo e espaço. Podemos dizer então, que o feirante constrói a sua reputação através de uma imagem que alimenta ao longo do tempo, imagem que tem para si mesmo e é apresentada aos outros. Uma imagem negociada diretamente com o grupo ao qual está inserido e que foi aceita, admitida e que possui credibilidade.

O mercado, a barraca e a casa dos feirantes se misturam na construção de suas memórias e na formação de suas histórias - é o que pôde ser observado quando questionados sobre como se tornaram feirantes. A Entrevistada 1 possui uma barraca há 25 anos e comercializa hortaliças folhosas, especiarias, farinhas e conservas. Ela afirma que na infância nunca teve contato com a produção agrícola, porém o contato com hortifrutigranjeiros tornou-se frequente depois de casar-se com um agricultor. Assim, ela "tomou gosto" pela produção agrícola e com o marido conseguiu uma barraca no mercado. Se, por um lado, ela só foi desenvolver esse "gosto" depois de adulta e casada, os seus 4 filhos sempre tiveram em casa o contato com a produção agrícola e com o mercado, mas, apenas a sua filha mais nova, a Entrevistada 7, acompanhou a mãe e cresceu entre os corredores do mercado.

Acompanhar a mãe desde muito pequena e estar inserida diariamente nas atividades do mercado foi o que permitiu que a Entrevistada 7 participasse de um cotidiano cheio de significações, cores, cheiros e texturas. Esse cotidiano pode ser encontrado nas falas dos feirantes mais velhos (Entrevistados 1, 3, 4 e 6) quando estes afirmam que a profissão de feirante se aprende no dia a dia, com o que todos os entrevistados definiram de "a lida do dia", que representa para eles o contato diário com a gestão da barraca, que envolve o ato de montar a banca, expor os produtos e criar vínculos com os clientes. Para corroborar tal afirmação, a Entrevistada 7 informa que sempre acompanhou a mãe no mercado, participando da montagem da barraca e da exposição dos produtos:

Eu vivi aqui dentro desde que aprendi a caminhar, vinha cedo, ajudava a organizar os produtos na banca, conversava com o freguês, ajudava no troco. Depois fui vendo as mulheres a fazerem as compotas, logo já sabia como fazer também. Em casa aprendi a plantar e colher com meu pai, no Mercado com minha mãe aprendi a ser feirante, vender, fazer compota, conversar, como arrumar a banca e aí eu vi, depois de mais velha, que era isso que sabia fazer de melhor, então não precisava fazer faculdade nem nada disso não, porque já tinha aprendido aqui minha profissão (Entrevistada 7, 23 anos, julho, 2015).

Os lugares onde vivemos são, para Candau (2005), uma forma de tornar as memórias consistentes. Se a identidade se forma através da memória, crescer e viver dentro do mercado cria a identidade de feirante e dá significações ao cotidiano e às práticas vivenciadas durante toda a vida dos feirantes. O mercado e o cotidiano formam para as pessoas que ali convivem o lugar de memória, como apontado por Nora (1993). O mercado recebe a marca dos feirantes e vice-versa (Halbwachs, 1990); assim, todas as ações dos feirantes podem ser traduzidas através do espaço que ocupam. 
As lembranças e os momentos vivenciados dão sentindo ao presente e criam horizontes futuros, mas esta não é uma lógica inflexível e o contrário também está sujeito a ocorrer, permitindo que os desejos futuros redefinam as lembranças, tornando a memória sempre um instrumento de ação e de escolhas (Godoi, 1999). Esse processo de aprendizado do cotidiano pode também ser refletido no papel da tradição, que como a memória, vive um processo constante de modificações e possui suas práticas em deslocamento e reapropriação à medida que sofre os impactos de transmissão de uma geração a outra (Giddens, 1995).

Logo, a noção e construção acerca da profissão de feirante, aqui representada pelos entrevistados, podem ser pensadas como um fenômeno cognitivo que liga o sentimento de pertencimento e a afetividade, "às interiorizações das experiências, das práticas, dos modelos de conduta e de pensamento, socialmente inculcados ou transmitidos pela comunicação social, que aí estão ligados” (Jodelet, 2001, p. 5). Assim, o que é passado para os filhos entre os feirantes está além do patrimônio físico da barraca; como afirma Carneiro (2001), outros tipos de bens que estão além dos bens materiais, os bens simbólicos, são transmitidos de uma geração a outra.

O patrimônio imaterial, aqui exemplificado através das características de ser feirante transmitidas aos filhos, é a junção dos eventos da vida cotidiana, o concreto e o simbólico, caracterizado como legado pelos feirantes. O patrimônio é fruto do exercício da memória que, ao longo dos anos e seguindo normas que se modificam, se vincula ao que é herdado do passado e então se configura em bens que devem ser transmitidos e protegidos (Candau, 2005). Esse patrimônio imaterial, que pode ser interpretado como o saber-fazer de ser feirante, como exposto na fala da Entrevistada 7, consiste nos aprendizados, saberes e experiências que são edificados no dia a dia do mercado (Vedana, 2013).

Assim, uma característica encontrada entre os feirantes é levar os filhos para o trabalho. A Entrevistada 6 - que também se tornou feirante ao se casar, pois o marido já era feirante no mercado - possui na gerência de sua barraca apenas filhos e noras, pois teme delegar essa responsabilidade a desconhecidos. Ela afirma que todos os 6 filhos eram trazidos para o mercado desde pequenos, mas à medida que foram envelhecendo foram buscando outros trabalhos na cidade. Atualmente, apenas o mais velho e o mais novo participam da gestão da barraca e estes trouxeram com eles às esposas. Esta barraca existe há mais de 40 anos e comercializa apenas especiarias e ervas. Os filhos ajudam na produção agrícola, organização da barraca e na comercialização dos produtos, e desde quando começaram a trabalhar são remunerados por aquilo que fazem.

Os Entrevistados 2 e 8 são filhos da Entrevistada 6; hoje ajudam os pais na barraca de especiarias, mas já possuem suas próprias barracas de hortaliças. Eles afirmam que sempre gostaram de ajudar os pais no trabalho do mercado, que nunca gostaram de estudar e por isso, mesmo com a permissão dos pais, não quiseram fazer faculdade, e pensaram em fazer outras coisas profissionalmente. Mas, como afirma um deles:

Eu gosto de trabalhar aqui porque aprendi desde muito cedo e é isso que sei fazer desde pequeno. Conversar com freguês, fazer brincadeira. O povo que eu já conhecia lá da barraca de pai e mãe já me conhece e vem comprar as verduras aqui comigo (Entrevistado 8, 28 anos, julho, 2015).

Os pais dos Entrevistados 6 e 8 alegam que apenas estes dois assumirão e herdarão a barraca e as rendas da comercialização, pois os outros filhos não se envolvem mais com esta atividade e possuem outras profissões. Logo, observa-se que a transferência do direito sobre um determinado patrimônio familiar de uma geração para outra se modifica de acordo com as condições de cada família, com as possibilidades de negociação ou de compensação disponíveis (Carneiro, 2001).

A fala do Entrevistado 8 permite mais uma vez encontrar a relação entre cotidiano, memória e a formação do feirante. $\mathrm{O}$ cotidiano forma os saberes da profissão, o conhecimento que deverá ser passado de geração para geração e, durante esse processo, esse conhecimento é ratificado ou acrescentado. A transmissão desse saber-fazer, da essência da profissão, é vista como mais importante do que a transferência do bem físico, pois a memória do saber-fazer é tênue. Assim, todo grupo que busca passar adiante seus conhecimentos profissionais define quais os procedimentos devem permanecer e quais podem ser esquecidos ou alterados na formulação 
da memória, para que a reprodução dos saberes e do saber-fazer reflita o melhor da profissão (Candau, 2005), abrindo espaço para as inovações das novas gerações.

Para os feirantes, entre todos os saberes e experiências adquiridos no cotidiano, a habilidade de intercâmbio, o "jogo social com fregueses e com os outros, a maestria de instaurar jocosidades e consolidar vínculos" (Vedana, 2013, p. 46), é a mais importante a ser transmitida e mantida entre as gerações. Tensões e discordâncias existem e são frequentes, embora sejam resolvidas a partir do "jogo social" entre os próprios feirantes e/ou consumidores. O mercado é burlesco e inspira, de acordo com cada feirante e cada consumidor, leveza ou malícia. Por isso, não raro, observam-se piadas, brincadeiras e certamente inversões de hierarquias que resultam em experiências singulares.

Para Vedana (2013), essa habilidade de lidar e identificar cada tipo de consumidor é uma capacidade construída no mercado, herdada e passada entre gerações.

Para os entrevistados a herança da barraca está ligada ao desejo de continuidade ou não dos filhos; nenhum dos feirantes colocou como obrigação para os filhos herdar a barraca. Alguns consideram que é importante cursar faculdade, buscar outras fontes de conhecimento e de renda, alegando que no mercado há muita "labuta", mas em seguida afirmam que a barraca representa a história da vida e da família, e o fato de ninguém assumir implica no fim da história, como indicam as falas abaixo:

Eu tenho orgulho do que eu faço, porque foi aqui que eu criei meus filhos, minha história e a deles está aqui, nessa banca! Se nenhum dos filhos assumir a barraca a história acaba né?!! (Entrevistada 1, 45 anos, julho, 2015)

Eu aprendi com meu pai, meu filho aprende comigo, o filho dele com ele, e assim vai, ficar aqui não é obrigado não, tem que aprender, aprender é importante, mas se quiser fazer outras coisas faz também, porque montar barraca e fazer a feira é querência $^{2}$, é vontade! Se não tiver a vontade não fica não! (Entrevistado 8, 28 anos, julho 2015).

Assim, herdar a barraca é um processo que representa mais do que herdar um negócio de cunho apenas econômico, consiste na perpetuação da história que essas barracas simbolizam. A história da família se torna a memória da família, e é na vida cotidiana que essa história se enraíza, formulando a identidade familiar, que se reinventa através das gerações. A história é construída através de lembranças, momentos em família, por vínculos com personagens que marcam cada um, como avós, tios, pais, e que convergem para que a memória se firme e se torne concreta. Para que a sociedade continue a existir, recordar e esquecer são eventos que caminham juntos e as características de um grupo existem na medida em que são produzidos e reproduzidos no presente (Candau, 2005; Mannheim, 1982).

Para os filhos entrevistados, herdar a barraca nunca foi uma imposição; o desejo de herdar surgiu quando perceberam que ser feirante era o que queriam como profissão. Para eles, outras profissões eram possíveis, assim como fazer um curso superior, mas preferiram ficar e ajudar os pais. Assim, a realidade desses entrevistados difere da realidade encontrada em outras pesquisas semelhantes. Na pesquisa de Melo (2013), por exemplo, desenvolvida no nordeste brasileiro, a baixa escolaridade verificada entre os feirantes se devia ao fato de a profissão ser uma atividade daqueles que não tiveram a chance de frequentar a escola. Ainda na pesquisa de Melo, a maioria dos pais entrevistados não leva os filhos para auxiliá-los nos trabalhos diários, o que impede que o mercado assuma perante os jovens o papel de espaço de cotidianidade, de memória e de sociabilidade.

O que se percebe através dos relatos dos entrevistados em Montes Claros é que a oportunidade de ajudar os pais no trabalho diário cria um clima pedagógico favorável para a continuidade da profissão e da tradição familiar. A prática é parte do processo para a formação do feirante, que irá conectar a reconstrução contínua do passado com a ação prática, tornando concreto o saber-fazer adquirido nesse processo diário (Giddens, 1995). Cada grupo social, e mesmo profissional, possui tradições específicas a serem seguidas e que podem ser compreendidas através da história e das relações entre os membros desse grupo. Assim, o comportamento, ou uma característica cultural de um grupo, não se constitui através da história da tradição, mas sim da história 
da relação da qual a prática se originou e possibilitou a transformação desta em uma tradição revivificada no cotidiano (Mannheim, 1982).

Logo, aceitar e desejar herdar, seja um patrimônio físico ou simbólico, estão ligados à maleabilidade da natureza humana. As normas de comportamento não são hereditárias, e sim moldadas através da capacidade de aprender e adquirir padrões. Herdar a barraca e se tornar feirante é um processo longo de formação, que ocorre através de uma ancoragem da representação e do seu objeto em uma rede de significações que os situa em relação a valores sociais. A ancoragem é um instrumento do saber (Jodelet, 2001) e, ao se partilhar com um sucessor conhecimentos e ideias, se firma um vínculo social e uma identidade que contribui para a afirmação simbólica da pertença no tempo e no espaço.

É importante salientar que o Mercado Municipal se localiza no meio urbano, exatamente no centro da cidade de Montes Claros. Os jovens aqui entrevistados são de origem rural, ainda residem na zona rural, mas convivem diariamente em um ambiente urbano, estudam em escolas localizadas no centro da cidade, frequentam festas, bares, shoppings da cidade, mas gostam e querem trabalhar no mercado e também na produção agrícola. No caso específico desta pesquisa, os jovens transitam entre dois espaços, e suas decisões de permanência na profissão não podem ser simplesmente interpretadas como resultado de uma falta de opção, mas sim como exercício da reflexividade na medida em que se utilizam as atividades cotidianas para orientar os projetos de vida entre ficar e sair, o que se quer ser e como agir (Giddens, 1995).

Há, portanto, nas falas dos jovens entrevistados, uma ausência de sentimentos de inferioridade por viverem conjuntamente o rural e urbano, o que reforça os apontamentos de Stropasolas (2013). Para o autor, reduzir as percepções de rural e urbano ou tradição e modernidade a um dualismo gerou apenas estigmas entre populações e modos de vida, não sendo capaz de explicar as complexidades vivenciadas pelos jovens rurais, que se movimentam dinamicamente entre distintos espaços sociais, criando e inovando visões de mundo que se refletem nas suas escolhas profissionais e projetos de vida. O mercado é a junção entre rural e urbano, o que torna esse lugar dinâmico, em constante reestruturação, que incorpora novos valores, hábitos e práticas.

Segundo os feirantes, essas incorporações mostram que o mercado dialoga com o tempo, ou seja, representa uma parte da cultura e tradição da cidade, mas também é preciso inovar. Todos os entrevistados apontaram que atualmente se deve buscar melhores formas de comercialização, e melhorias na estrutura física, para receber as pessoas com maior conforto. Segundo eles, em termos comparativos, os grandes supermercados podem não oferecer produtos tão frescos e saborosos, mas oferecem praticidade. Quando indagados sobre o que modificou nos últimos anos com relação à vinda das pessoas ao mercado, os entrevistados responderam que poucas modificações aconteceram. As pessoas que vinham há 15 anos atrás ainda são as mesmas e que alguns clientes já enviam os filhos em seu lugar para comprar. Há, nesse caso, uma relação de fidelidade entre feirante e consumidor que também perpassa as gerações.

Segundo os entrevistados, a principal modificação é a intensidade de ida das pessoas. Essa modificação afetou diretamente a condição de vida dos feirantes, que afirmaram que já viveram em condições melhores do que a atual. A diminuição da frequência pode estar diretamente vinculada à praticidade que os supermercados oferecem, como estacionamentos e facilidade nas formas de pagamento. A necessidade dessa praticidade pode ser entendida, de acordo com Giddens (1995), pelo fato de que as sociedades influenciam e são influenciadas pela inserção das instituições modernas nos acontecimentos da vida cotidiana. Vedana (2013) observou, em sua pesquisa sobre feiras livres, que o capitalismo contemporâneo possibilita facilmente nas cidades a entrada de supermercados e de todas as suas vantagens sobre comércios tradicionais, diminuindo os espaços, atenção e políticas públicas voltadas para mercados municipais e feiras livres.

Os efeitos negativos da presença e da competição dos supermercados podem ser amenizados pela relação pessoal, de contato face a face e de fidelidade entre consumidor e feirante. Silvestre (2013), em sua pesquisa a respeito da feira livre no Vale do São Francisco/MG, afirma que o feirante se preocupa em comercializar produtos de qualidade e em criar um vínculo com o consumidor, uma relação de amizade que estabelece compromisso entre o cliente e sua fidelidade, o feirante e sua reputação e os próprios bens comercializados. 
Assim, observa-se que, direta ou indiretamente, o conhecimento sobre o feirante e sobre seus métodos por parte do consumidor é o que institui condições para um processo amistoso de negociação entre as partes, o que não é possível nas grandes redes de supermercados.

\section{Conclusões}

Ao focalizarmos o processo de herança e sucessão das barracas no Mercado Municipal de Montes Claros, foi possível perceber que os patrimônios material e imaterial são igualmente importantes e transmitidos de geração para geração. O patrimônio imaterial dos feirantes é construído por memórias, símbolos, práticas e conhecimentos que atravessam o tempo, as gerações e as transformações sociais. Por sua vez, esse patrimônio dá origem ao sentimento de pertença dos feirantes e cria a relação de afetividade com o espaço em que convivem e com a profissão que exercem. Já o patrimônio material - a barraca e o mercado - vinculado à gestão econômica e à história das famílias forma o lugar de memória, e este lugar faz da história do grupo uma memória consistente e cognitiva.

As entrevistas obtidas neste trabalho possibilitaram compreender que não apenas o pesquisador que busca as informações encontra um sentido na memória, mas também os próprios entrevistados que, ao reviverem suas histórias, ou as do grupo no qual estão inseridos, fazem redescobertas e reafirmam as escolhas que fizeram. As representações aqui analisadas estão atreladas ao cotidiano, à identidade, à memória individual e coletiva sobre o espaço físico e simbólico que é o mercado.

Neste trabalho percebemos que, em um grupo como os feirantes, herdar significa mais do que dar continuidade e gerir um ponto de comércio com função estritamente econômica; significa também dar continuidade à memória da família. Os jovens aqui entrevistados, ao escolherem permanecer no mercado e se tornarem feirantes, dão continuidade também à própria história do mercado. A história de vida dos feirantes e a história institucional do mercado se misturam e se complementam, e permitem que esse espaço permaneça vivo.

Esse artigo termina como uma forma de instigar novas pesquisas para compreender os processos de herança e sucessão entre jovens e adultos de origem rural, cujas vidas convergem diariamente para o meio urbano mercado municipal - onde diferentes campos de possibilidades profissionais se apresentam aos jovens, mas que, paradoxalmente, decidem manter a tradição profissional dos pais.

\section{REFERENCIAS}

Anjos, F. S. dos, Godoy, W. I., e Caldas, N. V. (2005). As feiras-livres de pelotas sob o império da globalização: perspectivas e tendências. Rio Grande do Sul: Editora e gráfica universitária.

Angulo, J. L. G. (2003). Mercado local, produção familiar e desenvolvimento: estudo de caso da feira de Turmalina, Vale do Jequitinhonha, MG. Organizações Rurais e Agroindustriais, 5(2), 96-109. Recuperado de: http://revis ta.dae.ufla.br/index.php/ora/article/view/242

Araújo, E. J. C., e Ichikawa, E. Y. (2011). Compreendendo o projeto redes de referência para agricultura familiar a partir das representações sociais dos atores envolvidos. Organizações Rurais e Agroindustriais Revista de Administração da UFLA, 13(1), 39-52. Recuperado de: http://revista.dae.ufla.br/index.php/ora/article/view/304

Candau, J. (2005). Antropologia da memória. Lisboa: Instituto Piaget.

Caneiro, M. J. (2001). Herança e gênero entre agricultores familiares. Revista Estudos Feministas, 9(1), 22-55. Doi: h ttp://dx.doi.org/10.1590/S0104-026X2001000100003

Cazane, A. L., Machado, J. G.de C. F., e Sampaio, F. F. (2014). Análise das feiras livres como alternativa de distribuição de frutas, legumes e verduras (FLV). Informe GEPEC, 18(1), 119-137. Recuperado de: http://e-revista.unioes te.br/index.php/gepec/article/view/7355 
Cordisco, M. et al. (2013). Cultura, identidad y territorio: reflexiones para el desarrollo de una estrategia de diferenciación del servicio agroturístico en emprendimientos de un Grupo de Cambio Rural (INTA) del partido de Coronel Suárez (Buenos Aires). Mundo Agrario, 14(27). Recuperado de: http://www.mundoagrario.unlp.e du.ar/article/view/MAv14n27a02/4831

Chemin, B. F., e Ahlert, L. (2010). A sucessão patrimonial na agricultura familiar. Revista Estudo e Debate, 17(1), 49-74. Recuperado de: http://www.univates.br/revistas/index.php/estudoedebate/article/viewFile/13/3

Ferraris, G. (2011). La identidad y la memoria. Una experiencia de campo en el norte cordobés. Mundo Agrario, 11(22). Recuperado de: http://www.mundoagrario.unlp.edu.ar/article/view/v11n22a05/255

Filgueiras, B. S. C. (2006). Do mercado popular ao espaço de vitalidade: o mercado central de Belo Horizonte (Dissertação de mestrado inédita). Programa de Pós-graduação em Planejamento Urbano e Regional. Universidade Federal do Rio de Janeiro. Rio de Janeiro, RJ.

Froehlich, J. M. (2002). A (re)construção de identidades e tradições: o rural como tema e cenário. VI Congreso de La Asociación Latinoamericana de Sociología Rural (ALASRU), Brasil. Recuperado de: http://www.alasru.org/p $\mathrm{df} /$ congreso2002.pdf

Fulgêncio, D. L. (2000). Mercado Municipal. Revista Nossa História: Montes Claros, 1, 17-37.

García, R. W. D. (2003). Reflexos da globalização na cultura alimentar: considerações sobre as mudanças na alimentação urbana. Revista Nutrição, 16(4). Doi: http://dx.doi.org/10.1590/S1415-52732003000400011

Giddens, A. (1995). Modernidade reflexiva: política, tradição e estética na ordem social moderna. São Paulo: Editora da Universidade Estadual Paulista.

Godoi, E. P. (1999). O trabalho da memória: cotidiano e história no sertão do Piauí. Campinas: Editora Unicamp.

Hansen, R. S. (2002). El espacio público en el debate actual: una reflexión crítica sobre el urbanismo post-moderno. EURE Revista Latinoamericana de Estudios Urbano Regionales, 84(28), 5-19. Doi: http://dx.doi.org/10.4067 /S0250-71612002008400001

Halbwachs, M. (1990). A memória coletiva. São Paulo: Editora Vértice.

Instituto Brasileiro de Geografia e Estatística - IBGE. 2010. Censo Demográfico. Recuperado de: http://www.cida des.ibge.gov.br

Jodelet, D. (2001). As representações sociais. Em D. JODELET (Ed.), As representações sociais (pp. 17-41). Rio de Janeiro: EdUERJ.

Mannheim, K. (1982). O problema sociológico das gerações. Em M. Marialice Foracchi (Ed.). Karl Mannheim: Sociologia (pp. 67-95). São Paulo: Ática.

Mascarenhas, G. (2008). Feira livre: territorialidade popular e cultura na metrópole contemporânea. Ateliê Geográfico Goiânia-GO, 2(2), 72-87.

Melo, S. P. (2013). Juventude e feiras do sertão alagoano: laços de conflitos e reprodução social. Revista Cadernos de Ciências Sociais da UFRPE. 2(3), 28-48. Recuperado de: .http://www.journals.ufrpe.br/index.php/ cadernosdecienciassociais/article/view/3 47/278

Minayo, M. C. de S. (2010). O desafio da pesquisa Social. Em M. C. de S Minayo (Ed.). Pesquisa social: teoria, método e criatividade (pp.9-29). Petrópolis: Vozes.

Nagel, B., Gonçalves, D., Rangel, P., e Peçanha, T. (2007). Os bastidores de uma feira livre: consumidores e feirantes falam sobre o velho hábito de ir à feira. Revista Eclética Cenas Urbanas, 24, 52-56. Recuperado de: http://pucriodigital.com.puc-rio.br/media/13\%20 \%20os\%20bastidores\%20de\%20uma\%20feira\%20livre.pdf

Nora, P. (1993). Entre memória e história: a problemática dos lugares. Projeto História, 10, 7- 28. Recuperado de: h ttp://revistas.pucsp.br/index.php/revph/article/view/12101/8763

Pollak, M. (1992). Memória e identidade social. Revista Estudos Históricos, 5(10), 200-212. Recuperado de: http:// bibliotecadigital.fgv.br/ojs/index.php/reh/article/view/1941/1080

Servilha, M. M. (2008). As relações de trocas materiais e simbólicas no mercado municipal de Araçuai - MG. (Dissertação de Mestrado Inédita). Universidade Federal de Viçosa, Viçosa, MG, Brasil. 
Silvestre, L. H. A., Ribeiro, A. E. M. e Freitas, C. S. (2012). Subsídios para a construção de um programa público de apoio à feira livre no Vale do São Francisco, MG. Revista Organizações Rurais e Agroindustriais, 13(2), 186-200. Recuperado de: http://revista.dae.ufla.br/index.php/ora/article/view/346/316

Silvestro, M. L. et al. (2001). Os impasses da sucessão hereditária na agricultura familiar. Brasília: NEAD - Ministério do Desenvolvimento Agrário.

Stropasolas, V. L. (2013). A crise da sucessão geracional e suas implicações na reprodução social da agricultura familiar. IXXIX Congresso Latinoamericano de Sociologia. Associação Latinoamericana de Sociologia, Santiago - Chile. Recuperado de: http://actacientifica.servicioit.cl/biblioteca/gt/GT5/GT5_StropasolasV.pdf

Vedana, V. (2013). Fazer a feira e ser feirante: a construção cotidiana do trabalho em mercados de rua no contexto urbano. Revista Horizontes Antropológicos, 19(39), 41-68. Doi: http://dx.doi.org/10.1590/S0104-71832013 000100003

\section{Notas}

1 Varejões e Sacolões são formas de comércio de alimentos hortifrutigranjeiros existente no Brasil.

2 O termo querência utilizado pelo feirante significa querer, mas também significa lugar onde nasceu, lugar pelo qual se possui afeto. 